- Short communication

\title{
CONTAMINATION OF DHANMONDI AND GULSHAN LAKE WATERS WITH SOME METALS AND INORGANIC POLLUTANTS
}

\author{
MUHAMMAD ZAMIR HOSSAIN*, GAZI MD. AHSANUL KABIR AND \\ SHAMSHAD BEGUM QURAISHI ${ }^{1}$ \\ Department of Chemistry, Jagannath University, Dhaka-1100, Bangladesh
}

\begin{abstract}
Air, soil and water are continuously being polluted by the anthropogenic activities and sometimes by natural calamities. Among the three components, water pollution perhaps is the most important one. The contamination of water resources and biota is of major concern especially in industrialized countries because of the discharge of toxic, persistent and bio-accumulative substances from various sources. Household wastes dumped by the city dwellers contribute also to a great extent to the pollution of urban areas.
\end{abstract}

Key words: Contamination, Lake waters, Metals, Inorganic pollutants

Water of Dhanmondi and Gulshan lakes is being contaminated due to increased human activities from construction works and visitors from last few years. Thus monitoring systems are essential to study long term pollution processes of lakes especially when they are affected by the impact of increasing tourists. Therefore, a monitoring program had been initiated in 2003 over a period of one year for a wide range of chemical determinants. The main objectives of this work were: (i) to establish background levels for heavy metals and some anions in two lakes of the Dhaka city and (ii) to examine seasonal variability of the metals in lake waters.

Dhanmondi and Gulshan lakes are two fresh water man-made lakes located within the residential area of Dhanmondi and Gulshan, respectively. The investigated sites of Dhanmondi lake were DP1, DP2, DP3 and of Gulshan lake were GP1, GP2 and GP3. Water samples were collected into acid washed plastic containers by dipping the containers at 0.5 meter depth. For determination of all parameters, one litre well-washed high density polyethylene (HDPE) containers were used for collection of water samples. From the collected water samples of $500 \mathrm{ml}$ was separated into another bottle and were preserved in a refrigerator after adding $2 \mathrm{ml} \mathrm{HNO}_{3}$. Standard reference materials SRM 1643d (trace elements in water) and SRM 1640 (trace elements in water) from National Institute of Standard and Technology (NIST), USA, were used to check the accuracy and precision of the analytical methods. $\mathrm{Na}, \mathrm{K}, \mathrm{Ca}, \mathrm{Mg}, \mathrm{Pb}, \mathrm{Cd}, \mathrm{Co}, \mathrm{Ni}, \mathrm{Cu}, \mathrm{Fe}, \mathrm{Mn}$ and $\mathrm{Zn}$ were measured in the water samples using AAS after digestion with $\mathrm{HNO}_{3}$; chloride,

\footnotetext{
* Author for correspondence : <zamir545@gmail.com>.

${ }^{1}$ Chemistry Division, Atomic Energy Centre, P.O. Box 164, Dhaka-1000, Bangladesh.
} 
fluoride and cyanide were measured with ion selective electrode (ISE); sulfate and phosphate were measured by turbid metric and ascorbic acid method, respectively. Conductivity and $\mathrm{pH}$ were also determined in the water samples.

$\mathrm{pH}$ values in samples of Dhamondi and Gulshan Lake waters were found 6 - 7 during the study period. Table 1 indicated that $\mathrm{pH}$ values in the water samples were neutral to slightly acidic in nature. Conductivity ranged from $195-504 \mu \mathrm{S}$ in both the lakes (Table 2). The concentration of $\mathrm{CN}^{-}$ranged from $0.031-0.170 \mathrm{ppm}$ and 0.090 $0.367 \mathrm{ppm}$ for Dhanmndi and Gulshan Lake, respectively. Minimum level was observed in Dhanmondi Lake in November. Elevated levels of cyanide were found in February and September i.e. in pre- and post-monsoon period. Most lake water samples had $\mathrm{CN}^{-}$ concentration above the drinking water guideline value $(0.1 \mathrm{ppm})$ of Bangladesh (Bangladesh Gazzete 1996). Pre-treatment is necessary for using water of these two lakes for drinking purpose. Mean $\mathrm{F}^{-}$concentration was higher in Dhanmondi Lake. (Table 1) and its contents decreased gradually from June to November for both lakes and it might

Table 1. Level of different anions, conductance and $\mathrm{pH}$ in water samples at different locations of Dhanmondi and Gulshan lakes.

\begin{tabular}{|c|c|c|c|c|c|c|c|c|}
\hline Season & Location & $\begin{array}{c}\text { Cyanide } \\
\text { (ppm) }\end{array}$ & $\begin{array}{l}\text { Fluoride } \\
(\mathrm{ppm})\end{array}$ & $\begin{array}{c}\text { Chloride } \\
(\mathrm{ppm})\end{array}$ & $\begin{array}{l}\text { Sulphate } \\
\text { (ppm) }\end{array}$ & $\begin{array}{l}\text { Phosphate } \\
\text { (ppm) }\end{array}$ & $\begin{array}{l}\text { Conductivity } \\
(\mu \mathrm{S})\end{array}$ & $\overline{\mathrm{pH}}$ \\
\hline \multirow{5}{*}{ Nov. } & DP1 & 0.047 & 0.36 & 31.8 & 19.9 & 0.79 & 273 & 6 \\
\hline & DP 2 & 0.032 & 0.32 & 33.0 & 19.9 & 0.39 & 263 & 7 \\
\hline & DP 3 & 0.031 & 0.33 & 33.0 & 18.6 & 0.85 & 278 & 7 \\
\hline & GP 1 & 0.102 & 0.25 & 27.7 & 8.0 & 4.73 & 398 & 6 \\
\hline & GP 2 & 0.090 & 0.24 & 27.9 & 9.0 & 3.94 & 385 & 6 \\
\hline \multirow{7}{*}{ Feb. } & GP 3 & 0.103 & 0.22 & 32.0 & 9.0 & 6.7 & 404 & 7 \\
\hline & DP1 & 0.149 & 0.28 & 48.8 & 19.27 & 0.77 & 321 & 7 \\
\hline & DP 2 & 0.137 & 0.28 & 49.5 & 19.82 & 0.34 & 291 & 7 \\
\hline & DP 3 & 0.124 & 0.29 & 48.0 & 19.64 & 0.41 & 328 & 6 \\
\hline & GP 1 & 0.363 & 0.27 & 37.9 & 12.73 & 6.09 & 504 & 7 \\
\hline & GP 2 & 0.367 & 0.27 & 41.0 & 12.45 & 4.07 & 495 & 6 \\
\hline & GP 3 & 0.326 & 0.27 & 47.0 & 11.45 & 6.03 & 482 & 7 \\
\hline \multirow{5}{*}{ June } & DP1 & 0.048 & 0.26 & 38.6 & 20.00 & 0.37 & 284 & 7 \\
\hline & DP 2 & 0.047 & 0.24 & 41.1 & 24.20 & 0.37 & 325 & 6 \\
\hline & DP 3 & 0.046 & 0.26 & 38.8 & 22.02 & 0.50 & 315 & 7 \\
\hline & GP 1 & 0.140 & 0.20 & 24.9 & 12.94 & 3.12 & 336 & 6 \\
\hline & GP 2 & 0.145 & 0.21 & 26.8 & 12.94 & 3.99 & 362 & 6 \\
\hline \multirow{7}{*}{ Sept. } & GP 3 & 0.118 & 0.23 & 35.4 & 12.61 & 4.99 & 434 & 7 \\
\hline & DP1 & 0.170 & 0.12 & 24.2 & 15.88 & 0.84 & 195 & 7 \\
\hline & DP 2 & 0.157 & 0.11 & 23.7 & 16.91 & 0.76 & 211 & 6 \\
\hline & DP 3 & 0.154 & 0.11 & 23.1 & 17.53 & 0.42 & 219 & 7 \\
\hline & GP 1 & 0.360 & 0.10 & 13.3 & 9.69 & 1.68 & 238 & 7 \\
\hline & GP 2 & 0.291 & 0.09 & 13.9 & 10.52 & 1.09 & 232 & 7 \\
\hline & GP 3 & 0.240 & 0.09 & 11.3 & 8.25 & 1.93 & 271 & 6 \\
\hline
\end{tabular}

be due to dilution of the lake water during rainy season. Observed values for $\mathrm{Cl}^{-}$in both lakes were higher than the reported average value $(5.3 \mathrm{ppm})$ for Russian lakes 
(Weekstrom et al. 2003) but much lower than the Bangladesh drinking water guideline value of 150 - $600 \mathrm{ppm}$. Mean $\mathrm{Cl}^{-}$level decreased about twofolds in Dhanmondi Lake for last six years but slightly increased in Gulshan Lake (Banu 1999). The highest concentration of sulphate (24.2 ppm) was observed in Dhanmondi Lake in June and the lowest in Gulshan Lake in November (Table 1). It was observed that, sulphate level increased significantly in Dhanmondi and Gulshan Lake in 2004 compared to 1998 (Banu 1999). Phosphate concentration ranged from $0.34-0.85 \mathrm{ppm}$ and $1.09-6.70 \mathrm{ppm}$ in Dhanmondi and Gulshan Lake respectively during the study period. The mean concentration of phosphate of Dhanmondi lake was comparable to the level $(0.42 \mathrm{ppm})$ reported for Tuskegee Lake (Ikem et al. 2003) and maximum value in Gulshan Lake was found near to the corresponding value of Bangladesh drinking water standard $(6 \mathrm{mg} / \mathrm{l})$. Phosphate level increased two times higher in Gulshan Lake than in Dhanmondi Lake and it might be due to excessive use of detergents and phosphate fertilizers in vegetation and nursery on the bank of Gulshan lake.

Concentrations of $\mathrm{Na}$ ranged from 14.43 - $81.34 \mathrm{ppm}$ and 19.45 - $58.52 \mathrm{ppm}$ in Dhanmondi and Gulshan lake, respectively (Table 2). It was observed that there was slight variation in $\mathrm{Na}$ contents among the seasons and collection points. The highest concentration was observed at DP1 location in September and at the same location in November but the average value was higher in Gulshan lake. Average values for both lakes were higher than those of the previous study (Banu 1999). Observed $\mathrm{Na}$ content was $3.3 \pm 0.24 \mathrm{ppm}$ in Taskegee lake in USA (Ikem et al. 2003) and $3.5 \mathrm{ppm}$ in lake Kola peninsula in Russia (Ikem et al. 2003) but observed values did not exceed the value of Bangladesh drinking water standard of $200 \mathrm{ppm}$. In this study, the highest K content was observed at GP3 location in September and the lowest at DP1 location in November. Mean content in both lakes were three times higher than the value of previous study (Banu 1999). Average observed values exceeded the values of Global lakes. Maximum and minimum values of $\mathrm{Ca}$ was found at DP1 locationin September and in June respectively. Previous value for $\mathrm{Ca}$ was higher for Dhanmondi Lake and lower for Gulshan lake. Drinking water guideline value for $\mathrm{Ca}$ is $75.0 \mathrm{ppm}$ and all the values were within this limit. Almost similar seasonal variation was observed in both lakes and concentrations were almost same compared to the previous study (Banu 1999).

Toxic elements such as $\mathrm{Pb}, \mathrm{Cd}, \mathrm{Cr}, \mathrm{Co}, \mathrm{Ni}$ and $\mathrm{Cu}$ were found below the detection limit of the equipment used (Table 1). Detection limits of these elements were also below the Bangladesh drinking water standards. Concentration of Fe ranged from $0.017-0.984$ ppm and 0.07 - 1.7 ppm in Dhanmondi and Gulshan lake, respectively. The highest concentration was observed at GP2 location in June and the lowest at GP3 location in November. Average Fe content increased two times in Dhanmondi lake four times in Gulshan lake compared to the last six years. Global and national published water standard 
Table 2. Level of different metals (in ppm) in water samples at different locations of Dhanmondi and Gulshan lakes.

\begin{tabular}{|c|c|c|c|c|c|c|c|c|c|c|c|c|c|c|}
\hline Sea-son & $\begin{array}{l}\text { Loca- } \\
\text { tion }\end{array}$ & $\mathrm{Na}$ & $\mathrm{K}$ & $\mathrm{Ca}$ & $\mathrm{Mg}$ & $\mathrm{Pb}$ & $\mathrm{Cd}$ & $\mathrm{Cr}$ & Co & $\mathrm{Ni}$ & $\mathrm{Cu}$ & $\mathrm{Fe}$ & $\mathrm{Mn}$ & $\mathrm{Zn}$ \\
\hline \multirow{6}{*}{ Nov. } & DP1 & 14.43 & 7.05 & 16.94 & 1.77 & $<22.05$ & $<6.00$ & $<6.13$ & $<8.93$ & $<17.96$ & $<3.89$ & 0.017 & 0.029 & 14.23 \\
\hline & DP 2 & 27.99 & 10.57 & 16.94 & 2.86 & $<22.05$ & $<6.00$ & $<6.13$ & $<8.93$ & $<17.96$ & $<3.89$ & 0.069 & 0.004 & 43.58 \\
\hline & DP 3 & 17.97 & 10.57 & 19.19 & 2.99 & $<22.05$ & $<6.00$ & $<6.13$ & $<8.93$ & $<17.96$ & $<3.89$ & 0.105 & 0.061 & 96.71 \\
\hline & GP 1 & 25.02 & 13.71 & 24.84 & 0.68 & $<22.05$ & $<6.00$ & $<6.13$ & $<8.93$ & $<17.96$ & $<3.89$ & 0.483 & 0.015 & 95.46 \\
\hline & GP 2 & 19.45 & 8.62 & 20.33 & 1.96 & $<22.05$ & $<6.00$ & $<6.13$ & $<8.93$ & $<17.96$ & $<3.89$ & 0.310 & 0.106 & 52.56 \\
\hline & GP 3 & 29.61 & 13.71 & 29.36 & 1.09 & $<22.05$ & $<6.00$ & $<6.13$ & $<8.93$ & $<17.96$ & $<3.89$ & 0.070 & 1.76 & 32.63 \\
\hline \multirow{6}{*}{ Feb. } & DP1 & 26.13 & 8.95 & 48.02 & 17.16 & $<22.05$ & $<6.00$ & $<6.13$ & $<8.93$ & $<17.96$ & 7.78 & 0.553 & 0.031 & 10.09 \\
\hline & DP 2 & 27.77 & 10.32 & 46.61 & 18.55 & $<22.05$ & $<6.00$ & $<6.13$ & $<8.93$ & $<17.96$ & $<3.89$ & 0.812 & 0.033 & 11.41 \\
\hline & DP 3 & 27.77 & 10.67 & 40.96 & 17.51 & $<22.05$ & $<6.00$ & $<6.13$ & $<8.93$ & $<17.96$ & $<3.89$ & 0.466 & 0.038 & 9.66 \\
\hline & GP 1 & 46.66 & 12.73 & 46.61 & 11.75 & $<22.05$ & $<6.00$ & $<6.13$ & $<8.93$ & 21.11 & $<3.89$ & 0.949 & 0.177 & 63.20 \\
\hline & GP 2 & 45.84 & 13.76 & 28.25 & 7.03 & $<22.05$ & $<6.00$ & $<6.13$ & $<8.93$ & $<17.96$ & 5.18 & 0.484 & 0.177 & 52.42 \\
\hline & GP 3 & 43.21 & 10.32 & 29.66 & 6.91 & $<22.05$ & $<6.00$ & $<6.13$ & $<8.93$ & $<17.96$ & $<3.89$ & 0.501 & 0.167 & 38.18 \\
\hline \multirow{5}{*}{ June } & DP1 & 23.98 & 10.73 & 30.05 & 10.92 & $<22.05$ & $<6.00$ & $<6.13$ & $<8.93$ & $<17.96$ & 7.96 & 0.984 & 0.058 & 13.46 \\
\hline & DP 2 & 24.94 & 9.60 & 12.99 & 11.99 & $<22.05$ & $<6.00$ & $<6.13$ & $<8.93$ & $<17.96$ & $<3.89$ & 0.826 & 0.059 & 15.46 \\
\hline & DP 3 & 28.30 & 10.17 & 13.56 & 2.31 & $<22.05$ & $<6.00$ & $<6.13$ & $<8.93$ & $<17.96$ & $<3.89$ & 0.791 & 0.064 & 10.02 \\
\hline & GP 1 & 38.58 & 10.73 & 14.69 & 6.00 & $<22.05$ & $<6.00$ & $<6.13$ & $<8.93$ & $<17.96$ & $<3.89$ & 0.826 & 0.213 & 47.81 \\
\hline & GP 2 & 47.49 & 15.82 & 14.69 & 9.38 & $<22.05$ & $<6.00$ & $<6.13$ & $<8.93$ & $<17.96$ & $<3.89$ & 1.7 & 0.212 & 31.21 \\
\hline \multirow{7}{*}{ Sep. } & GP 3 & 58.52 & 15.29 & 15.82 & 7.38 & $<22.05$ & $<6.00$ & $<6.13$ & $<8.93$ & $<17.96$ & $<3.89$ & 0.316 & 0.140 & 16.60 \\
\hline & DP1 & 81.34 & 72.99 & 61.17 & 1.89 & $<22.05$ & $<6.00$ & $<6.13$ & $<8.93$ & $<17.96$ & $<3.89$ & 0.234 & 0.016 & 75.13 \\
\hline & DP 2 & 37.16 & 71.47 & 42.82 & 12.63 & $<22.05$ & $<6.00$ & $<6.13$ & $<8.93$ & $<17.96$ & $<3.89$ & 0.144 & 0.024 & 34.61 \\
\hline & DP 3 & 35.99 & 65.39 & 55.06 & 20.90 & $<22.05$ & $<6.00$ & $<6.13$ & $<8.93$ & $<17.96$ & $<3.89$ & 0.378 & 0.026 & 33.54 \\
\hline & GP 1 & 38.62 & 53.22 & 53.02 & 15.10 & $<22.05$ & $<6.00$ & $<6.13$ & $<8.93$ & $<17.96$ & $<3.89$ & 0.558 & 0.111 & 35.95 \\
\hline & GP 2 & 40.96 & 85.15 & 46.90 & 11.61 & $<22.05$ & $<6.00$ & $<6.13$ & $<8.93$ & $<17.96$ & $<3.89$ & 1.64 & 0.054 & 38.10 \\
\hline & GP 3 & 43.31 & 150.55 & 42.82 & 7.69 & $<22.05$ & $<6.00$ & $<6.13$ & 16.85 & $<17.96$ & $<3.89$ & 0.288 & 0.069 & 40.25 \\
\hline
\end{tabular}

for Fe was 0.3 - 01 ppm (Rahman 1998, Reimann et al. 2003, Saeki and Okzaki 1993, Menikol et al. 1998, Quraishi et al. 2006). In some locations, Fe exceeded this range and steal workshops beside the lake might be the reason for such high concentrations. Maximum Mn content was observed in Gulshan lake and minimum in Dhanmondi lake in November. Mn content increased four times in Gulshan Lake for last six years but it was still below the drinking water standard value set at $0.1 \mathrm{ppm}$. Mean Mn content $(0.271$ ppm) was higher in Gulshan lake than in Dhanmondi lake (0.037 ppm) and were comparable with the value $(0.01 \mathrm{ppm})$ reported for the Tangyan lake in China (Chale 2002). The highest and the lowest concentration of $\mathrm{Zn}$ were recorded in Dhanmondi lake in November and in February, respectively. The overall $\mathrm{Zn}$ content was three times higher in Gulshan Lake than those of last six years (Banu 1999). Observed values were higher compared to reported values but didn't exceed the drinking water value for Bangladesh set at $5 \mathrm{ppb}$.

Lake water quality parameters such as $\mathrm{pH}$, conductivity, 13 metals $(\mathrm{Na}, \mathrm{K}, \mathrm{Ca}, \mathrm{Mg}$, $\mathrm{Pb}, \mathrm{Cd}, \mathrm{Cr}, \mathrm{Co}, \mathrm{Ni}, \mathrm{Cu}, \mathrm{Fe}, \mathrm{Mn}, \mathrm{Zn})$ and 5 anions $\left(\mathrm{F}^{-}, \mathrm{Cl}^{-}, \mathrm{CN}^{-}, \mathrm{SO}_{4}{ }^{2-}\right.$ and $\left.\mathrm{PO}_{4}{ }^{3-}\right)$ concentration in Dhanmondi and Gulshan lakes were reported. A clear seasonal variation was observed for K, Ca and for all anions except phosphate in both lakes. Present study 
indicated that the levels of different toxic and essential elements, in most cases, were within the permissible limit. Although the concentrations were mostly below the established maximum permissible level, a systematic monitoring for toxic elements is recommended due to their potential high toxicity. The concentrations of $\mathrm{Fe}, \mathrm{Mn}, \mathrm{CN}^{-}$, $\mathrm{PO}_{4}{ }^{3-}$ were high in both the lakes indicating the necessity of further detailed investigation of these parameters and the extent of water quality impairment for use in domestic, bathing and drinking water purposes.

\section{REFERENCES}

Bangladesh Gazzete, 1998. Govt. of People's Republic of Bangladesh, Dhaka, Bangladesh, Edition, August 28: 3124-3127.

Banu L. S., 1999. M.Sc. Thesis, Department of Chemistry, Jagannath University College, Dhaka.

Chale F. F. M. 2002. The Sci. Total Environ. 299: 115.

E. Steinnes, A. Henriksen, Water, Air and Soil Pollution 71: 167. 1993

Ikem A., N. O. Egiebor and K. Nyavor. 2003. Water, Air and Soil Pollution, 149: 51.

Menicol D. K., M. L. Mallory, C. Laberge and D. Cluis. 1998. Water, Air and Soil Pollution, 105: 343.

Quraishi S. B. 2008. Bang. J. Academy of Science, 32(1): 33.

Quraishi S. B., M. N. Chowdhury, S. Akhter, M. K. Khan. 2006. Nucl. Sci. and Appl, 15(2): 82.

Rahman M. M. 1998. M.Sc. Thesis, Department of Applied Chemistry and Chemical Technology, Dhaka University.

Reimann C., Bjorvatn, B. Frengstad and Z. Melak. 2003. The Sci. Total Environ. 310: 1.

Saeki K. and M. Okazaki, 1993. Water, Air and Soil Pollution, 69: 69.

Weekstrom J., J. A. Snyder, A. Korhola, T. E. Laing and G. M. Macdonald. 2003. Water, Air and Soil Pollution, 149: 339.

(Received revised manuscript on 10 December, 2009) 